\title{
La aljama de los judíos de Alba de Tormes en la Edad Media
}

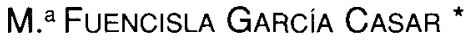

RESUMEN

Alba de Tormes fue una de las veinticuatro localidades salmantinas que contó con población judía a lo

largo de los siglos medievales.

Destacó la pujante aljama por su activa participación en los asuntos del concejo, por la estima que alcanzaron

sus médicos, por la confianza de la que hizo gala el Estudio salmantino al confiar a judios albenses la recaudación de sus rentas $y$, muy especialmente destacó, por ser con toda probabilidad el origen de la familia Zacut, cuyo miembro más preclaro fue el astrónomo y matemático Abrahán Zacut, cuyos cálculos astronómicos manejó su contemporáneo Cristóbal Colón.

\section{ABSTRACT}

Alba de Tormes has been one of 24 localities of Salamanca which counted with Jewish population during the medieval centuries. The puissant aljama was conspicuous because of its active participation in the counsel affairs, the esteen that has been caugth up with their Jewish doctors, the reliance that was the pride of the Studies of Salamanca, by trusting to Jewish from Alba de Tormes the collection of their rents and specially, probably because of being the little country of the great astronomic and mathematic Abrahán Zacut, whose astronomical calculations were managed by his contemporaneous Christopher Colombus.

La actual provincia de Salamanca, aledaña por todo su lado occidental al reino de Portugal, a las provincias de Zamora y Valladolid por su lado norte, a la de Ávila por el este y a la de Cáceres por el oeste, contó al correr de los siglos medievales con veinticuatro localidades con población judía, atestiguadas documentalmente: Alba de Tormes, Béjar, Cantalapiedra, Ciudad Rodrigo, Fuenteguinaldo, Gallegos de Solmirón, Hinojosa de

* Universidad de Salamanca. 
Duero, Ledesma, Linares de Riofrío, Miranda del Castañar, Monleón, Montemayor del Río, La Orbada, Paradinas de San Juan, Peñaranda de Bracamonte, Puente del Congosto, Salamanca, Salvatierra de Tormes, San Felices de los Gallegos, San Muñoz, Santiago de la Puebla, Tamames, Tejeda y Villoria ${ }^{1}$.

De muy irregular distribución por la geografía salmantina, estos asentamientos se concentran en la ribera o en las cercanías de los ríos más importantes que la bañan. Así, en las riberas del río Águeda están San Felices de los Gallegos, Ciudad Rodrigo ${ }^{2}$ y Fuenteguinaldo. En el río Huebra los de San Muñoz, Tamames y Tejeda, con población judía más modesta. Junto al Alagón, Monleón y Miranda del Castañar. Por último, en las riberas del salmantino Tormes figuran las poblaciones con comunidad judía más importante: Salamanca ${ }^{3}$, Ledesma, Salvatierra de Tormes, Puente del Congosto y la que es objeto de este estudio, Alba de Tormes.

La villa está situada en el extremo NE. de una fertilísima vega, en la margen derecha del río Tormes, a 21 kilómetros de Salamanca. Una suave colina de $30 \mathrm{mts}$. de altura sobre el nivel del río le sirve de asiento. Su término confina al $\mathrm{N}$. con los de Palomares, Martín Valero y Alquería de Lagartera; por el E. con los de Amatos, Garci Hernández y Aldeaseca; por el S. con los de Navales, Martín Vicente, Patillo y Egeme, y por el O. con los de Terradillos, Valdemienque y Martín Amor.

Las cordilleras de Guadarrama y Francia realzan en magnífica vista, su entorno natural con el verde de montes y praderas que matizan sus llanuras. No sin razón esta belleza mereció toda la veracidad poética de Garcilaso y Lope de Vega. Abundan los viñedos y los árboles frutales, cereales, legumbres y hortalizas. En las márgenes del río crecen álamos, alisos, chopos, fresnos y sauces, y los arroyos Fontanilla, Cornezuelo, torrejón y Terradillo cruzan el término.

Fue Alba villa cercada por recia muralla torreada - hoy casi inexistente-, con cinco puertas, algunas aún en buen estado con sus arcos y cubos laterales para su defensa. Calles empinadas y plazas albergan iglesias románico-mudéjares como la de San Juan, del siglo XII, siendo la de Santiago, al este, la de mayor antigüedad. De arraigada tradición conventual femenina, la del Carmelo, fundado en 1570 por Teresa de Jesús,

\footnotetext{
Vid. Mapa de los asentamientos en C. CARrete Parrondo, Fontes ludaeorum Regni Castellae, I: Provincia de Salamanca [= FIRC I], Salamanca 1981, p. 145.

2 Vid. M. ${ }^{a}$. F. García CASAR, FIRC VI: El pasado judio de Ciudad Rodrigo, Salamanca 1992.

3 Vid. M. ${ }^{a}$. F. García CASAr, El pasado judio de Salamanca, Salamanca 1987 (reimpresión: 1988).
} 
hace de la villa de Alba un lugar de peregrinación. En una arqueta de mármol jaspeado, situada en el centro del retablo mayor, reposan los restos de la gran mística castellana ${ }^{4}$.

Completan su pasado monumental un puente de 22 arcos tirado a cordel sobre el río Tormes, que apenas conserva nada de su traza medieval, y en un altozano que domina la vega por el lado $S$., el castillo y el palacio del duque de Alba. Se halla en ruinas y tan deteriorado que sólo se conserva un torreón cilíndrico de los seis que hicieron exclamar a Garcilaso en su Égloga II: Allí está sobrepuesta la espesura / de las hermosas torres, levantadas al cielo con extraña hermosura.

En la Alvia vaccea de Ptolomeo se quiere ver su antiquísima fundación. Pero su historia documentada se remonta a los días del repoblador de Salamanca, el conde borgoñón don Raimundo, suegro de Alfonso VI. La conquista de Toledo en 1085 hizo posible la repoblación definitiva entre el Duero y el Tajo, lo que dio lugar al nacimiento de grandes concejos: Plasencia, Escalona, Madrid, Oreja, Alcalá, Hita, Guadalajara, Segovia, Riaza, Cuéllar, Ávila, Arévalo, Zamora, Ciudad Rodrigo, Salamanca y Alba de Tormes.

Será Alfonso VII quien en 1140 conceda fuero a esta villa. En tres de sus cláusulas - 12, 39 y 40- se legisla en igualdad de condiciones sobre los judíos que ya residían en ella mediado el siglo $\mathrm{XI}^{5}$.

Las noticias sobre la albense comunidad judía durante el siglo XIII son muy escasas y de carácter económico. En 1278, reinando Alfonso X, habiendo surtido poco efecto la real cédula de 1 de mayo de 1260 , en la que se recuerda que los cristianos no deben dar a usura por ley ni derecho y se tasa el interés a moros y judíos, mandó el rey por encargo del Papa, hacer pesquisas en Alba sobre el mencionado abuso, pero se suspendieron por orden del infante don Sancho que se hallaba en Astorga y a quien sin duda recurrieron los vecinos, en atención a que este fecho caía en tantos omes e en tales, que el daño de ellos tañía a todos los que eran en la villa y en el término, e si aquellos lo oviesen a pechar por sí, que serian astragados e que sería despoblamiento de la villa ${ }^{6}$. Esto evidencia, como es-

4 Vid. P. MADOZ, Diccionario geográfico-estadístico-histórico de Castilla y León, V: Salamanca, Valladolid 1984, s. v. "Alba de Tormes", pp. 33-42.

5 A. CASTRO, Fuero de Alba de Tormes, en Fueros leoneses de Zamora, Salamanca, Ledesma y Alba de Tormes, edic. y est. de y F. Onís, Madrid 1916, I, pp. 297 y 308-309, publ. en C. Carrete Parrondo, FIRC I, doc. 5, pp. 19-20.

6 J. M. a QuAdrado, Salamanca, Ávila y Segovia, Madrid 1885, p. 275, n. 1, publ. en C. Carrete Parrondo, FIRC I, doc. 1, p. 19, y vid. A. Ballesteros BeretTA, Alfonso X el Sabio, $2 .^{\circ}$ ed., 
cribe Baer, que a pesar de todo - el logro fijado en el tres por cuatro en las Cortes de Valladolid de 1258 era letra muerta - la monarquía castellana tenía interés en los privilegios que garantizaban la vida y la hacienda de los judíos, y en especial la de aquellos que tenían estrecha relación con los negocios de préstamo ${ }^{7}$.

El año de 1285 se caracteriza desde el punto de vista económico por opresivas ordenanzas en materia de impuestos, tan gravosos para aljamas de núcleos pequeños de la zona occidental del reino castellano-leonés, que a veces toda la aljama de los judíos se diseminaba al acercarse el recaudador de impuestos, como sucedió en la Trasierra del reino de León, donde el recaudador de impuestos anduvo allá de un lugar a otro buscando los judíos ${ }^{8}$.

Según los Libros de Cuentas de Sancho IV, los judíos de Alba contribuyeron ese año de 1285 con 66 mrs. y medio ${ }^{9}$, aparte de 1.200 que tenían que dar por razón de la tierra çierta de don Johan Ferrández de Limia, que bien pudiera ser don Juan Fernández, apodado Cabellos de oro $^{10}$, mayordomo del rey don Sancho y merino de Galicia. En 1293 los judíos albenses y los de Salamanca pagaron $17.973 \mathrm{mrs} .{ }^{11}$.

La muerte de Juan I en octubre de 1391, la minoría de edad de su sucesor Enrique III, los intereses poco claros del consejo de regencia, la grave inflación monetaria que obligó a acuñar moneda en los años 1386 y 1390 y las acentuadas diferencias religiosas llevadas al grado máximo de intolerancia, favorecieron el estallido del violento movimiento social antijudio de carácter popular del año 1391. No tenemos datos suficientes que nos permitan una valoración objetiva de la intensidad que tales sucesos alcanzaron en las tierras salmantinas. Abraham Zacut en su Séfer Yuhasín ('Libro de Linajes) se limita a decir que se persiguió a los judios en todo el reino de León: Astorga, Mayorga, Benavente, Toro, Zamora, Salamanca, Alba, Ciudad Rodrigo, en el año de la muerte del rey ${ }^{12}$. Lo cierto es que en 1399 Enrique III confirma el privilegio de doña

\footnotetext{
Barcelona 1984, p. 1081, y A. Barrios Garcia et alii, Documentación medieval del Archivo Municipal de Alba de Tormes, Salamanca 1982, doc. 6, pp. 43-44.

Historia de los judios en la España cristiana, Madrid 1981, I, p. 94.

8 Vid. F. CANTERA Burgos, "Juderías medievales de la provincia de León", Archivos Leoneses 55-56 (1974), pp. 85-155.

9 M. GalBrols, Historia del reinado de Sancho IV de Castilla, Madrid 1928, I, p. CLXXVII, y F. BAER, Die Juden im christlichen Spanien $[=J c h S]$, Berlín 1936, II, p. 72, publ. en C. Carrete Parrondo, FIRC I, doc. 2, p. 19.

10 F. Baer, JchS II, p. 90, publ. En C. Carrete Parrondo, FIRC I, doc. 3, p. 19.

11 Vid. C. Carrete Parrondo, FIRCI, doc. 4, p. 19.

12 Ed. H. Filipowski, Londres 1857, p. 221 a.
} 
Constanza, hija de don Enrique, señora de la villa de Alba, sobre la cabeza de pecho de la aljama, donando de él $4.000 \mathrm{mrs}$. al convento de San Esteban de Salamanca ${ }^{13}$.

Las persecuciones de 1391 y la aparición de la primera gran generación conversa ocasionaron grandes cambios en la distribución geográfica de las juderías castellanas, incrementándose el número de judíos no «ruanos» que preferían habitar en núcleos rurales con la categoría de pueblo, villa o aldea, forjándose así la secular movilidad del judío castellano.

Al alborear el siglo xv la hasta entonces floreciente aljama salmantina comienza a experimentar una acusada decadencia. Las predicaciones de Vicente Ferrer provocan tal número de conversiones que la sinagoga mayor se transformaría en el Colegio de la Veracruz de la Orden de Nuestra Señora de la Merced (actual Facultad de Ciencias, sección de Matemáticas), según sostiene la tradición, no respaldada hasta la fecha por dato documental alguno ${ }^{14}$; y en 1413 la casa del "Midrás" de la aljama es cedida por Juan II al Estudio salmanticense con el fin de edificar el Hospital de Santo Tomás de Aquino, para estudiantes pobres enfermos. Según consta en el documento, el rector, el maestrescuela y doctores de la Universidad solicitaron a la Corona tal edificio "por quanto los judíos de la çibdat eran conuertidos a la santa fe católica, tanto que no avia en ella salvo muy pocos judíos" 15 .

Mientras esto ocurría en la ciudad tormesina, en Alba su comunidad judía vivía días de pujanza y bienestar. La documentación, en ocasiones inédita, que aquí presento, procedente en su mayor parte del Archivo Municipal de Alba de Tormes, da buena prueba de ello.

A lo largo de todo el siglo XV es particularmente activa la participación de los judios albenses en el arriendo de las Rentas de Propios. Las rentas del peso de la cera, del aceite, del hierro, del pan, del peso de la lana, de la sal, de los cotos y de la vendimia fueron sacadas entre 1407 y 1408 por los judíos don Biuas, don Çag Madrotiel, don Salomón Madrotiel y don Çag Xeteui ${ }^{16}$. En 1460 arrendaban la renta del sotillo e vareaje don Daví Alcabaça, Symuel Sacud, su yerno, e Ysaque Husyllo ${ }^{17}$.

13 AHN, Clero, pergs., carp 1.897, núm. 2; AHN, Cód. 256-B, fol. 9ss.; AHN, Cód. 968-B, for. 52v, publ. en C. Carrete Parrondo, FIRCI, doc. 6, p. 21.

14 Vid. M. ${ }^{2}$. F. Garcia CASAR, El pasado judío de Salamanca, pp. 103-105.

15 Ibidem p. 114, publ. en C. Carrete Parrondo, FIRCI, doc. 277, pp. 110-111.

16 Archivo Municipal de Alba de Tormes [= AMAlba de Tormes], Actas, publ. en C. Carrete Parrondo, FIRC I, pp.21-22.

17 AMAlba de Tormes, Actas 1460, marzo 10 
En las reparaciones del castillo, del puente y de la cerca o muralla, los judíos contribuyen como un vecino más. Así en 1420 los regidores dixeron que por quanto el castillo desta villa necesita obras, los de la villa e sus vecindades, asi pecheros como escuderos e dueñas e doncellas e clérigos e judios e judías de Alva e su tierra, çinco mill nueveçientos e setenta mrs. ${ }^{18}$. En 1459, en el repartimiento de $25.000 \mathrm{mrs}$. para el reparo de puente e çerca, a los judíos les correspondió pagar 1.200 mrs., igual cantidad que a los clérigos ${ }^{19}$. Al año siguiente continúan las obras durante el verano, demandando el descuento de los $200 \mathrm{mrs}$. para la aljama de los judíos, por quanto están agraviados con excesivos impuestos ${ }^{20}$.

Continuo goteo de dinero fueron los pedidos e monedas para la comunidad judía: el pedido de las 15 monedas ${ }^{21}$, el pedido de las 7 monedas de la judería ${ }^{22}$, el pedido de la cabeça de pecho fijado en 4.000 mrs. y cedido por merçet e helimosina por doña Constanza, hija del rey don Enrique, al convento de San Esteban de Salamanca ${ }^{23}$, y el pedido de la «honra del rey» que en 1416 ascendía a $25.000 \mathrm{mrs}^{24}$. Dos años después el concejo pide a la reina y al arzobispo eximan a la aljama de pagar tal impuesto. Petición inútil, porque a los pocos meses en la sinoga de los judios de la dicha villa, estando ý la aljama della junta en oración, paresçió y Alfón Ferrandes, notario, e presentó ý e leer fiso la carta de la señora reyna en la que solicita de la aljama quatro mill mrs. que la aljama debe del pedido, si non, dixo que protestaua de los auer e cobrar dello, e de sus bienes con las costas que sobrello fuesen ${ }^{25}$.

Desde 1408 se suceden los nombres de los empadronadores de la judería - don Abrahán Sacud, Yhudá Gabay y don Çag Escapa- y los nombres de los cogedores de los impuestos de la aljama: don Çag Nunbel, Çag Ahuelo, don Yuçaf Portero y don Çag Çerulla ${ }^{26}$. Este mismo año Salomón

AMAlba de Tormes, Actas, s. t.

AMAlba de Tormes, Actas, s. f.

AMAlba de Tormes, Actas, s. $f$.

AMAlba de Tormes, Actas, s. f., enero 10, publ. en C. Carrete Parrondo, FIRC I, doc. 40 ,

p. 26.

AMAlba de Tormes, Actas, s. f., enero 6, publ. en C. Carrete Parrondo, FIRC I, doc. 47, p. 28.

${ }^{23}$ AHN, Clero, pergs., carp. 1.897, núm. 8, publ. en C. Carrete Parrondo, FIRC I, doc. 57, pp. 31-32.

24 AMAlba de Tormes, Actas, s. f., mayo 22.

25 AMAlba de Tormes, Actas, s. f. Para el pedido señorial ordinario (años 1407-1438) vid. J.

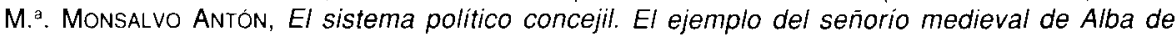
Tormes y su concejo de Villa y Tierra, Salamanca 1988, pp. 367-368, y para los repartimientos fiscales a privilegiados y judios (años 1420-1460) ibidem, pp. 406-411.

26 AMAlba de Tormes, Actas, d. F., publ. en C. Carrete Parrondo, FIRC I, doc. 12, p. 21. 
Madrotiel es recaudador mayor de la señora doña Beatriz, mientras que de las alcabalas y tercias de los obispados de Salamanca y Ciudad Rodrigo lo son Semuel Çelama y su socio don Yhudá Nahín, quien encarga al primero recoger las de Alba. A su vez Pedro Sánchez delega su poder en don Yuçaf Abolafia de Sevilla y éste, de nuevo, en Çelama ${ }^{27}$. Precisamente don Yuçaf Abolafia de Sevilla, recaudador del rey en los obispados de Salamanca y Ciudad Rodrigo del pedido de las 15 monedas da poder a don Salomón Madrotiel para que lo cobre en Alba de Tormes y su tierra, con Santiago de la Puebla y Peñaranda de Cantarcillo, entre otras localidades ${ }^{28}$.

En la ciudad del Tormes, judíos y Estudio mantuvieron siempre cordiales relaciones. Desde el siglo XIII llama la atención dentro del mundo artesanal, el número de pergamineros judíos, lo que podría explicarse por el auge cada vez más creciente del Estudio y su constante necesidad de materia prima para la labor escrituraria y libresca de profesores y bachilleres, sin olvidar que el comercio de códices, antes de la invención de la imprenta, cuya existencia en Salamanca se remonta al año $1483^{29}$, estuvo muy controlado por los comerciantes judíos.

Y el Estudio, fiel a esa ya vieja y feliz relación, no duda en acudir a los judíos a la hora de recaudar sus tercias de Alba y su tierra entre los años 1438 y 1440. El 5 de junio de 1438 el administrador de la Universidad otorga poder a don Habrahén, vecino de Alba, para que pueda coger y recaudar la renta de Alua e su tierra, con Santiago de la Puebla e Peñaranda de Cantarasillo e con todos los otros señoríos ${ }^{30}$. Al mes siguiente las rentas del Estudio pertenecientes a Aldea de Yuso y Carpio fueron recaudadas conjuntamente por don Dauid, judío, vecino de Alua, e Gonçalo de Alua, vecino de Salamanca ${ }^{31}$. En abril de 1439 arrendaron las rentas Açequiel e Yuçé abín Crespín, vecinos de Alba ${ }^{32}$, y en junio don Dauid aben Baça, siendo fiador de la puja Juçá aben Crespín, criado de don Abraham, vecino de Alua ${ }^{33}$.

En cuanto a lo que rentaron las tercias del Estudio en Alba y su tierra el año de 1440 he aqui su detallada relación:

\footnotetext{
27 C. Carrete Parrondo, FIRC I, docs. 13,16 y 16, p. 22.

28 Ibidem, doc. 21, p. 23.

29 Vid. M. ${ }^{a}$. F. GARCIA CASAR, "Observaciones sobre los incunables hebreos en España», El Olivo IX/21 (1985), pp. 63.72.

30 Archivo Universitario de Salamanca [= AUS], lib. 1.648, fol. 65r, publ. en C. Carrete Parrondo. FIRCI, doc. 5, p. 32.

31 AUS, lib. 1.648, fol. 78r, publ. en C. Carrete Parrondo, FIRC I, doc. 59, p. 32.

32 AUS, lib. 1.648 , fol. 9r, publ. en C. Carrete Parrondo, FIRC I, doc. 60, p. 32.

33 AUS, lib. 1.648, fol. 110r, publ. e C. Carrete Parrondo, FIRC I, doc. 61, p. 32.
} 
Haýn e Elias e Yuçé Steçud [sic], judíos, vecinos de Alua, se obligaron por doscientos nouenta mrs. por la terçia del Estudio de Turra.

Juçá Abencrespín es obligado por quinientos mrs. por la terçia de Hela Rodrigo.

Juan del Castillo, vecino de Galín de Yuste e Dauit Abenasar e Yuçé Matrutiel se obligaron por seiscientos mrs. por la terçia de Santibáñez e Carcala.

Atrafías, veçino de Valuerde, e Yuçé Atía, como su fiador, se obligaron por mill mrs. por la terçia de Valuerde.

Gonçalo Gomes e Yuçé Atía se obligaron çiento e nouenta mrs. por la terçia de Matarala.

Salomón, físico, e Rica, su mujer, se obligaron por mill e seiscientos mrs. por la terçia de Gallegos ${ }^{34}$.

$Y$ de estos trajines económicos de altos vuelos vengamos a los afanes menestriles y cotidianos de la villa, dominada entonces por la masa imponente del castillo. Entre las profesiones desempeñadas por los judíos albenses a lo largo del siglo xv los documentos recogen los siguientes: en 1411 don Çag Ahuelo era platero. En 1413 se habla de ciertos judios alfayates de la villa. Un documento de este mismo año nos dice que Samuel Çalama, vecino de Alba, desempeña el oficio de "emisario", especie de antiguo correo. Los regidores ordenan que se le de çient mrs. para su costa por que ha de llevar al rey de Aragón una petición quel conçejo le enbía en rasón del alguasiladgo de Alva ${ }^{35}$. En 1420 Abrahán Secud es «texedor» ${ }^{36}$, y Jacó Rosyllo es el «judío ferrero" en $1422{ }^{37}$. En 1454 se menciona a doña Rica, la maestra ${ }^{38}$. En 1458 los regidores mandaron dar a maestre Colýn, çerrajero, çiento e çinquenta mrs. por que tenga rasón de reparar e conçertar el relox de aquí ${ }^{39}$. Por un documento de 1459 podemos pensar que el yerno de don Ybrael, llamado Bienveniste, se dedicaba a alguna actividad relacionada con el oficio de la cantería porque recibe del concejo doscientos e çinquenta mrs. en satisfacción de çiertas carretadas de piedra que

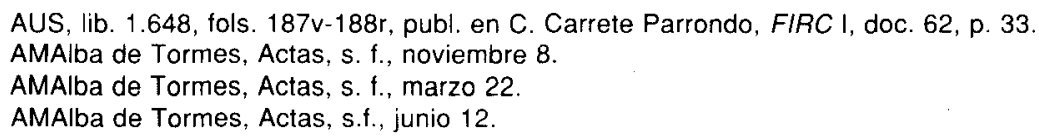

- Este escueto dato revela la existencia de una bet-séfer o escuela de niños (Archivo de la Universidad Pontificia de Salamanca [= AUPSalamanca], cód. 154, fols. 44v-45r, publ. e C. Carrete Parrondo, FIRC I, doc. 65 , p. 33

39 AMAlba de Tormes, Actas, s.f., julio 7. 
fue para la çerca ${ }^{40}$. En 1460 Abrahán Borro e Ysaque Borro, su hijo, figuran como carniceros de la aljama ${ }^{41}$. En 1485 eran curtidores Harón y Yuçé de Monleón ${ }^{42}$.

$Y$ entre las profesiones liberales, el ejercicio de la medicina por judíos, pese a lo legislado en contra por las Cortes, goza de enorme credibilidad en las tierras salmantinas. Si en 1472 el propio rector del Estudio da por buena la declaración de Rabí Abrahán, médico, vecino de la ciudad de Salamanca, sobre el estado de salud del maestro Juan de León, profesor de la cátedra de Filosofía, aquejado de perlesía ${ }^{43}$, años antes la población cristiana de Alba de Tormes ya se ponía en manos del saber médico de sus judíos. El concejo no sólo paga escrupulosamente sus servicios, sino que también renueva sus contratos. En 1408 don Salamón, çerugiano, vesino de Alua, recibe del concejo trescientos mrs. ${ }^{44}$. En noviembre de ese mismo año el concejo y Rabí Osúa, físico, fijo de Rabí Abrahán, acuerdan que el judío sea médico de la villa durante tres años por 2.000 mrs. anuales. Entre los testigos figura Salomón Madrotiel ${ }^{45}$. En 1411 don Salamón, çelurgiano, y Rabí Osúa, físico, vecinos de Alba, reciben de Ferrand Alonso, mayordomo del concejo, el primero $600 \mathrm{mrs}$, y el segundo $1.000 \mathrm{mrs}$, de los mrs. quel dicho conçejo nos ha de dar de nuestras soldadas. El 11 de marzo el primero recibe otros $1.000 \mathrm{mrs}$. y el segundo $300 \mathrm{mrs}$. En diciembre Rabí Osúa es reelegido médico para que sirua el ofiçio en la villa e su tierra ${ }^{46}$.

Eran éstas profesiones tan estimadas que sus titulares gozaban de exenciones tributarias. Asi en 1411 pusieron en renta las siete monedas de la judería de la villa, sin las casas de don Salamón, çelurgiano, de Rabí Osúa, físico, e que todos los otros que paguen e non sean quitos. E que paguen en las dichas monedas aquí, en Alua, todos los judios e judías que han morado e moran en el término de la villa, salvo si ovieron pagado en otra parte ${ }^{47}$.

Siendo Alba de Tormes villa condal desde 1429, en virtud del título que como tal le otorgara don Juan II a don Fernando Álvarez de Toledo, el

\footnotetext{
40 AMAlba de Tormes, Actas 1459.

AMAlba de Tormes, Actas 1460

42 AUPSalamanca, cód. 154 , fols. $46 \mathrm{v}-47 \mathrm{r}$, publ. en C. Carrete Parrondo, FIRC I, doc. 70, p. 34.

43 AUS, Libros de Claustros I, fol. 225r-v, y vid. III, fol. 90v (20 octubre 1479), publ. e C. Carrete Parrondo, FIRC I, doc. 338, p. 121.

${ }_{44}$ AMAlba de Tormes, Actas, S. f., noviembre 21, publ. en C. Carrete Parrondo, FIRC I, doc. 24, p. 23.

${ }_{45}$ AMAlba de Tormes, Actas, s. f., noviembre 30, publ. en C. Carrete Parrondo, FIRC I, doc. 26, p. 24

${ }_{46}$ AMAlba de Tormes, s. f., publ. en C. Carrete Parrondo, FIRCI, docs. 43 y 45, pp.27-28.

47 AMAlba de Tormes, s. f., enero 6, publ. en C. Carrete Parrondo, FIRC I, doc. 47, p. 28.
} 
por entonces segundo conde don García media en 1460 en unas desavenencias entre el concejo y maestre Ysaque, físico, a causa de su escasa designación anual, dos mill e quatroçientos mrs., que el conde eleva a tres mill mrs. por año, por quanto él [maestre Ysaque] se quería yr disiendo que non se podía mantener ${ }^{48}$.

Seis años más tarde, cuando la villa condal está a punto de convertirse en ducado en la persona del mencionado segundo conde don García, por merced de Enrique IV, el concejo contrata a Rabí Yudá como boticario, asentando dos mill mrs. de salario por que luego traya su muger a la villa, e tenga continuo tienda poblada de su ofiçio ${ }^{49}$.

Hasta 1489 no volvemos a tener noticias del físico maestre Ysaque. Ese año la contaduría de la reina abona a maestre Ysaque, judío, vecino d'Alva de Tormes, çinco mill mrs. de merced, para yr çierto camino, lo que hace suponer que sus servicios fueron reclamados por la nobleza ${ }^{50}$.

¿Cómo fue la vecindad? La comunidad judía de Alba de Tormes no fue ajena al suceder de la historia, ni al ir y venir de la villa y su población cristiana, sus intereses - bien o mal intencionados- y sus afanes. Si bien es cierto que no hay noticia documental de disturbios y violencia contra la aljama de Alba a raíz de los sucesos de 1391, las disposiciones del Papa Benedicto XIII en la bula que promulga en 1415 sobre la guarda de libros hebreos en las catedrales, la imposición a los judíos de asistir a los sermones, la prohibición de llevar a cabo juicios en el interior de las aljamas y sobre el tema de la usura y contratos con cristianos, se dejan sentir de alguna manera esos agitados años del siglo $x \mathrm{~V}$, acrecentado todo ello además por las predicaciones del dominico Vicente Ferrer en la cercana Salamanca. Así, en Alba comienzan a pulular predicadores. El año 1413 es prolijo en detalles: en mayo los regidores ordenan a todos los judios e judias de Alva, de siete años arriba que vayan a oyr desde oy en adelante a las pedricaciones [sic] de Iñigo Lopes de Burgos ${ }^{51}$, mandato éste que se extiende también a los cristianos, como se desprende del documento de pago de haberes: quatroçientos mrs. para su costa de la estada que ha estado en Alua e ha de estar a predicar la fe de Dios nuestro señor, e la faser entender asi a los cristianos como a los judíos ${ }^{52}$. En junio llega a la

\footnotetext{
48 AMAlba de Tormes, Actas 1460, s. f.

AMAlba de Tormes, Actas, s. f., julio 29.

Cuentas de Gonzalo de Baeza, tesorero de Isabel la Católica, ed. de A. DE LA TORRE y E. A. DE LA TORRE, Madrid 1955, I, p. 261, publ. en C. Carrete Parrondo, FIRCI, doc. 71, p. 35.

AMAlba de Tormes, Actas, s. f., mayo 25.

52 AMAlba de Tormes, Actas, s. f., mayo 30.
} 
villa otro predicador, Tomé Rodríguez de Burgos, vecino de Madrigal de las Altas Torres, quien ejerció su oficio durante, al menos, medio año. Al finalizar su misión, los regidores mandan al alcalde que comunique a la aljama que dé al dicho Tomé Rodríguez çient mrs. para la dicha costa; e si non les quieren pagar que les tomen prendas e les enpeñen por ellos. Ese mismo documento aporta un dato interesante: otrosi que cate todos los libros del Talmud de los judíos e los muestre a Tomé Rodríguez para que quite dellos las oraciones queý están contra la fe de los cristianos ${ }^{53}$.

Sus más y sus menos hubo en el suministro de víveres y en las horas de mercado. Las medidas discriminatorias fueron poco a poco recrudeciéndose en todo el reino de Castilla, sobre todo en la década de los ochenta. En Medina del Campo quedó prohibida la venta de leña, carbón y pan en la judería. En Segovia -medidas parecidas se llevaron a cabo en Ávila y Soria - se les prohibió la compra de pescado los viernes y la venta de sal en la plaza. Salamanca fue un caso aparte, pues si hasta 1479 los judíos de la ciudad del Tormes tenían autorizada la compra desde el miércoles hora de vísperas hasta la hora tercia del jueves, el 3 de noviembre de 1480 una provisión real autoriza a los judíos a comprar sus víveres en cualquier día de la semana con total libertad.

En Alba y en 1411 los regidores, por quanto dixeron que era seruiçio de nuestra señora doña Beatriz e prouecho desta villa e de su tierra e de los que en ella biuen que de oy día en adelante alguno ni algunos moros ni moras, ni judíos ni judias de aqui, de Alua, ni de su tierra ni de otra parte alguna no compren antes de ora terçia cosa alguna en qualquier manera que sea, saluo pan cosido de las panaderías e fruta de las huertas e sal de las salinas e aseyte de las aceiteras e pescado de las percaderías de aquí, de Alua ${ }^{54}$. El 6 de marzo de 1422 el concejo prohíbe, esta vez a los cristianos, comprar las hortalizas de los judíos ${ }^{55}$.

En este sentido, la documentación conservada insiste a la hora de regular la entrada y la venta de vino en la villa, y las penas que gravan la introducción en la villa y en su tierra, de vino de fuera parte sin licencia del concejo. Se prohíbe con rigor que un judío utilizara vino cristiano. En 1410 el concejo da albalá a don Salomón Madrotiel porque podiese meter en Alva cada mes una carga de vino, sin pena. En diciembre se da licencia a don Mayr Lunbroso por que meta en Alua veynte cántaras

53 AMAlba de Tormes, Actas, s. f., junio 27

54 AMAlba de Tormes, Actas, s. f., enero 20, publ. en C. Carrete Pairrondo, FIRC I, doc. 50 p. 29

AMAlba de Tormes, Actas, s. $f$. 
de vino judiego para arestar una cuba; que faga juramento de 10 no meter christianiego ni que sea más de quarenta ${ }^{56}$. El 12 de octubre de 1459 los regidores protestan ante el conde que los judíos no almacenan suficiente cantidad de vino que les dure tanto como a los cristianos. El conde falló a favor de los cristianos e sy non fisiesen que les non diesen licencia para meter vino de fuera en tanto quel vino de la villa durase ${ }^{57}$. Es claro el problema económico que subyace en estas quejas. Como significativa es la insistencia que adquiere en la documentación manejada la prohibición de vender ese vino judiego a los cristianos. Si se prohíbe una y otra vez quiere decir que su venta a éstos estaba a la orden del dia. Pero habría que pensar que, tal vez, en ese vocablo «cristianos" se incluía tanto al cristiano viejo, el de dos capas de tocino grueso, como al judío recién convertido, al judeoconverso. Consumiendo ese vino kaser, ese vino bendecido con la oración de la berakah en el momento de llevarlo a la mesa, o siendo aún fruto de las viñas, sintiera que judaizando no perdía del todo su honda identidad judia. En 1413 Yuçé Çarfatí, en nombre de la aljama de Alba, nombra a Biuas y a Çalama, judíos vecinos de dicha villa, para que vendan el vino judiego en la dicha aljama ${ }^{58}$. Çalama jura que no lo venderá a ningún cristiano de Alba y su tierra.

Un judío de ese mismo año, Anbrán [sic], judio de Maqueda, trae cierto vino judiego para venderlo en Alba e fiso juramento segund su ley de lo non dar ni vender a christiano nin cristiana alguno ${ }^{59}$. Y el 24 de abril de 1459 los regidores autorizan al tabernero judío para que pueda meter vino en la villa todo el año, pero que echen excomunión en la synoga que ningund judio no traerá vino para christiano ni lo dará a christiano ${ }^{60}$.

Pese a todo, también había sus concesiones por parte del concejo: en 1420 se autoriza a Diego Flores y a Rabi Osúa, físico, y a Salamón, cirujano, para que metan sendos odres de vino para su vender ${ }^{61}$. $Y$ en 1416 los regidores ordenan que el carnicero de los judios que traya veinte e çinco cabeças de ganado ovejuno en los cotos e non más ${ }^{62}$.

56 AMAlba de Tormes, Actas, s. f. Para el año 1422 vid. J. M. ${ }^{a}$. Monsalvo Antón, El sistema político concejil. El ejemplo del señorio medieval de Alba de Tormes y su concejo de Villa y Tierra, pp. 476-477.

AMAlba de Tormes, Actas, s. $f$.

AMAlba de Tormes, Actas, s. f., junio 6.

AMAlba de Tormes, Actas, s. f.

AMAlba de Tormes, Actas, s. $f$.

AMAlba de Tormes, Actas, s. f., julio 2.

AMAlba de Tormes, Actas, s. f., agosto 14. 
Así mismo, no faltaron atenciones por parte de la Corona y la nobleza hacia judíos influyentes de la aljama y hacia ésta en su conjunto, donde un elevado porcentaje de sus miembros lleva el título de "don", como signo de distinción, pese a lo legislado en Cortes. En 1408 don Mayr Lunbroso, vecino de Alba, en nombre de la aljama de los judios presentó al concejo una carta de doña Beatriz, ordenando que non den posadores nin huéspedes algunos en las casas de los judíos e judias de aquí, de Alua ${ }^{63}$. Al año siguiente una carta de doña Beatriz ordena que non den ropa alguna al castellero [e.d.. alcaide] del alcáçar de la villa. En mayo el judío don Biuas es especialmente favorecido por doña Beatriz, al mandar que non diesen huéspedes algunos nin posasen en la posada de don Biuas, nin le tomasen sus ropas ${ }^{64}$.

De excelentes se pueden calificar las relaciones de los judíos albenses con el clero. Desde 1453 es muy corriente la venta de viñas propiedad de judíos al cabildo y clerecía de la villa. Éstos, a su vez, arriendan casas de su propiedad, en plena judería, a aquéllos, como Yuçé de Monleón y Clara, su mujer, que, en enero de 1485, se obligan con una tenería que nos avemos a la puerta de Barrios Çiegos, que a por linderos de la vna parte tenería de Harón e de la otra la dicha puerta de Barrios Çiegos ${ }^{65}$.

De los aspectos más humanos de la vida, asi como de la participación de los judíos en las fiestas de la villa, quedan dos preciosos testimonios: el códice de Actas Municipales correspondiente al año 1413 tiene cubierta de pergamino. Se trata más bien del fragmento de una ketubah o contrato matrimonial, escrito en letra cursiva rabínica española. Los textos laterales aparecen escritos en letra cuadrática. En un rosetón del ángulo superior izquierdo se lee en hebreo el versículo 16 correspondiente al capítulo 2 del Cantar de los Cantares: "Mi amado es mío y suya yo, él apacienta [su ganado] entre los lirios» ${ }^{66}$.

Salamanca y su tierra, en especial la comarca de la Charrería, es tierra de toros bravos. Pues bien, el ya mencionado don Biuas y Santo Rodríguez de Ávila son los encargados por el concejo en 1408 de dar dos toros buenos e brauos, tales que fuesen de dar e de tomar, para que lidiesen dia de Santa María de Candelaria que agora pasó o que pagasen seiscientos mrs. para comprar otros ${ }^{67}$. $Y$ en diciembre de ese mismo año don Biuas recibe

\footnotetext{
63 AMAlba de Tormes, Actas, s. †., julio 13, publ. en C. Carrete Parrondo, FIRCI, doc. 18, p. 22.

64 AMAlba de Tormes. Actas, s. f., publ. en C Carrete Parrondc, FIRCI, doc. 31, p. 25.

55 AUPSalamanca, cód. 154, fols. 46v-47r, publ. en C. Carrete Parrondo, FIRCI, doc. 70, p. 35.

66 C. Carrete Parrondo informa de su hallazgo en FIRC I, doc. 7, p. 21.

67 AMAlba de Tormes, febrero 3, publ. en C. Carrete Parrondo, FIRC I, doc. 14, p. 22.
} 
del concejo 1.600 mrs., 300 por vn toro que yo di al conçeio que corieron día de Santiago de agosto postrimero que pasó, y 1.300 mrs. que yo presté ${ }^{68}$, sin duda ninguna para los festejos de la villa.

Si echamos un vistazo a la capacidad económica de la aljama de Aba de Tormes la encontramos tributando en los repartimientos fiscales correspondientes a los años 1464, 1472, 1474, 1479, 1485, 1486, 1488, 1489,1490 y 1491 . En todos ellos recibe el calificativo de aljama. De los $2.400 \mathrm{mrs}$. del año 1464 pasa a 38.750 en 1491 , lo que la equipara en capacidad monetaria con la judería de la localidad salmantina de Villoria. Con ella tributa esta judería los años de 1486, 1490 y 1491. El resto de los años la comunidad judía de Alba tributa en solitario. Su estable y nada despreciable contribución fiscal, $40.000 \mathrm{mrs}$., sin altibajos notables, la colocan en sexto lugar después de la de Béjar, Salamanca, La Orbada, Tamames y Tejeda, seguida de la aljama de Ciudad Rodrigo ${ }^{69}$, de un total de veintiuna localidades con población judía en la provincia de Salamanca.

Hora va siendo ya de dar a esta comunidad judía un marco espacial. ¿Qué sabemos de su barrio, de su ubicación topográfica? Escasas y dispersas son las noticias que la documentación conservada nos proporciona acerca del lugar que ocupó en la villa la judería. Tenemos que esperar al 7 de marzo de 1413: en cartas que intercambian el concejo y el obispo de Palencia se plantea el apartamiento de la comunidad judia para cumplir así el Ordenamiento de doña Catalina sobre el ençerramiento de los judíos e de los moros de 1412: "que de aquí adelante todos los judíos e moros e moras de los mis Regnos e Señoríos sean e vivan apartados de los cristianos en un logar aparte de la çibdad, villa o logar, donde fueren vecinos, e que sean çercados de una çerca en derredor".

Se ordena en la villa que «los judíos se comiencen apartar e faser el çírculo en el lugar a do llaman La Bodeguilla, çerca de la puerta de Villoria». No conformes con el proceder del concejo, los judíos apelan al rey y a los infantes. El obispo de Palencia intercede preguntando al concejo si aquéllos podrían hacer el círculo donde tienen la sinagoga. El concejo responde que eso no es posible, porque precisamente aquel lugar "es lo más privado de la villa e non ay judería apartada, por quanto moran ý asás cristianos", y porque además ese lugar "es más seguido e usado para conversación de los cristianos que otro lugar de la villa. E si en el

68 AMAlba de Tormes, Actas, s. f., publ. en C. Carrete Parrondo, FIRC I, doc. 27, p. 24

69 Vid. el cuadro y notas "Repartimientos fiscales: provincia de Salamanca" en C. CARRETE PARRONDO, FIRC, I, pp. 145-150, y J. M. . Monsalvo ANTÓn, El sistema político concejil. El ejemplo del señorio medieval de Alba de Tormes y su concejo de Villa y Tierra, p. 378, n. 64. 
dicho lugar les fuere fecho el... çírculo e apartamiento a los... judíos... sería en grand escándalo e perjuiçio e conversación de los cristianos " 70 .

El concejo ofrece a los judíos otros dos lugares más para que hagan su círculo: el barrio de San Martín y la Torre nueva ${ }^{71}$.

Los datos aunque pocos, son muy interesantes pues nos pueden acercar, y mucho, al emplazamiento de la judería hasta aquel momento: detrás de la Plaza Mayor, en torno a la iglesia de San Juan, al oeste de la villa, intramuros, hacia el río Tormes.

En cuando a los dos nuevos lugares asignados, el barrio de San Martín estuvo situado, según documentos antiguos, en torno a la iglesia de igual advocación, al oeste, intramuros, cerca del castillo de los duques. En cuando a la Torre nueva podemos relacionarla con la fortaleza que se construyó en la villa, hacia el este, cerca de la iglesia de Santiago. Y del primer lugar asignado, La Bodeguilla, "çerca de la puerta de Villoria», a pesar de no encontrar más datos sobre este topónimo, si por «puerta de Villoria" se entiende aquélla por donde se salía en dirección a Villoria, hay que situarlo hacia el norte, cerca del actual cementerio.

Asi pues, tres lugares se ofrecieron a la aljama albense: La Bodeguilla, próxima a la Puerta de Villoria, el barrio de San Martín y la Torre Nueva "para que todos estos tres lugares los judíos escogiesen vno para do fesiesen el çírculo e apartamiento». Por último, aunque en un primer momento los judíos eligieron «las casas e corrales que fueron de Alonso Garçia, hijo de Sancho Garçía, con la signoga de los judíos e la calle que çerca della está", como los regidores contestaran que no es el lugar más conveniente porque «se recelan que los judíos recibieran algund daño o peligro», optaron por "el primer lugar", es decir su emplazamiento de toda la vida.

En 1416 la documentación da a entender que de algún modo se delimitó ese círculo en el antiguo emplazamiento y que no hubo traslado. Se habla de la "pared del çírculo donde viuen en la villa contra las casas e corrales de... Pero Ferrandes de Tolla ${ }^{72}$. Esto el 9 de mayo, porque el 19 del mismo mes «a la puerta del çírculo de los judíos de la villa que sale a las casas de Diego Flores, el pregonero apregonó que los judíos e judías çierren e atapen el çírculo en la manera que se contiene en las ordenanças del rey, en manera que persona alguna non entre nin salga dél por otra parte saluo por la dicha puerta, en manera que sea çerrado el

70 Doc. Publ. en C. Carrete Parrondo, FIRC I, doc. 56, pp. 30-31.

AMAlba de Tormes, Actas 1413.

AMAlba de Tormes, Actas 1416. 
çercado todo de oy a ocho días primeros siguientes" ${ }^{73}$. La aljama entonces emprende una serie de protestas contra tales disposiciones. Por un documento de 1418 podemos deducir que ese círculo que pretendia encerrar la judería era, aún, un proyecto. Los regidores mandan a Ferrant Alonso de Olivera "que apremie a los judíos e judías de Alua que çerquen el su çírculo e judería e que le pongan las puertas en él’ ${ }^{74}$. Que el círculo se llevara a efecto parece poco probable, guardando silencio la documentación posterior a 1418 .

Nada de especial sabemos de la suerte que corrió la comunidad judía de Alba a raíz del edicto de expulsión de 1492. En octubre de ese año el cabildo y clerecía alquila a Alonso de Alba y a Mari su mujer y a su hija Isabel "las casas del... cabildo que son en la judería... donde vivía Brido, judio" ${ }^{75}$. En 1494 se menciona a Rui Gonçales de Portillo, condenado por hereje ${ }^{76}$. Por un documento de 1496 sabemos que la judería pasó a denominarse "Barrionuevo": el cabildo de Alba de Tormes arrienda a "Mari Gomes, cristiana nueuamente convertida, el ayre de vna casa que el cabildo tiene en esta villa cabe la plaçuela que agora llaman Barrionueuo" ${ }^{77}$.

Dejemos estos tristes y desconocidos días porque, a pesar de todo, hasta la comunidad judía de Alba llegó el bullicio de la Salamanca del Estudio, allá por los días del siglo XV. La deliciosa novelita, acaso cervantina, La Tía fingida dice: "En Salamanca... cursan en ella y habitan diez o doce mil estudiantes, gente moza, antojadiza, arrojada, libre, liberal, aficionada, gastadora, discreta, diabólica y de humor». Pues bien, uno de los pupilos del Estudio, el bachiller Juan de Trasmiera, residente en la ciudad del Tormes, a ruego y pedimiento de un señor, trobó el pliego de cordel titulado «Este es el pleyto de los judíos con el perro de Alua, y de la burla que les hizo". Sin calidad literaria ninguna, en pareados octosílabos se recoge el sentir popular, hostil a todo lo judío, avalado por una tradición tópica y estereotipada ${ }^{78}$.

\footnotetext{
73 AMAlba de Tormes, Actas 1416.

74 AMAlba de Tormes, Actas 1418, julio 26.

75 AUPSalamanca, Cód. 154, fol. 84r-v, publ. en C. Carrete Parrondo, FIRCI, doc. 72 , p. 35.

76 Archivo General de Simancas, Registro General del Sello, fol. 26, publ. en C. Carrete Parrondo, FIRCI, doc. 73, p. 35.

77 AUPSalamanca, Cód. 154, fol. 95v, publ. en C. Carrete Parrondo, FIRCI, doc. 74, p. 35. Vid. J. L. LACAVE, Juderias y sinagogas españolas, Madrid 1992, p. 269.

${ }_{78}$ Vid. texto en C. Carrete Parrondo, FIRCI, doc. 75 , pp. 35-40, y M.a. F. Garcia Casar, el pasado judio de Salamanca, pp. 97-99. Y antes en J. Gómez-MEnOR, Cristianos nuevos y mercaderes de Toledo, Toledo 1970, pp. 109-117.
} 
De todo ello se acuñó el dicho «esto no vale más que las Coplas del perro de Alba", proverbial frase salmantina de los días clásicos, y que todavía hoy puede escucharse en boca del pueblo sencillo.

Pero la aljama judía de Alba de Tormes, antes de desaparecer, brilló con luz propia en uno de sus más preclaros miembros. Es cada vez más probable que de Alba de Tormes procediera la familia del famoso astrónomo y matemático contemporáneo de Colón, Abrahán Zacut, autor del compendio latino Almanach perpetuum, de su obra en hebreo Hibbur hagadol («El gran tratado»), y que dedicó al obispo de Salamanca don Alonso de Vivero. Al menos, este apellido con diferentes grafías - Sacud, Secud, Stecud, Çecud, muy próximas al hebreo Zekut- sólo aparece ampliamente documentado en Alba de Tormes. Si su nacimiento se sitúa entre 1450/1452, tal vez algún día se pueda demostrar su grado de parentesco - nieto e hijo respectivamente- con don Abrahán Sacud (empadronador de la judería en 1408) y don Symuel Secud (arrendador en 1460) de nuestros documentos ${ }^{79}$.

79 De hecho su nombre completo era Abraham bar Samuel bar Abraham Zacut. Zacuto parece ser una retranscripción de las formas latinas "Zacutus" y "Zecutus". (Vid. F. Cantera, Abraham Zacut, Madrid 1935). 